Journal of Development and Communication Studies, Vol. 8. No. 2, July -December, 2021 ISSN (Online \& Print): 2305-7432. http://www.devcomsjournalmw.org

\title{
Strengthening Communication and Information Capacities in Malawi: Case of the Malawi National Commission for UNESCO
}

Emmanuel Kondowe, EBZVisions Media Consultancies, Lilongwe, Malawi. Email: ezumanikondowe@gmail.com

\begin{abstract}
UNESCO is the only United Nations (UN) agency to have a global network of national cooperating bodies known as National Commissions. The National Commissions are part of the overall constitutional architecture of the organization as it was conceived by its founders. Presently, National Commissions operate in all Member States of UNESCO. They constitute a truly global family which includes a vast network of stakeholders, partners and experts. They offer a comparative advantage to the organisation within the United Nations system. Article VII (1) of the UNESCO Constitution stipulates that "Each Member State shall make such arrangements as suit its particular conditions for the purpose of associating its principal bodies interested in educational, scientific and cultural matters with the work of the organisation, preferably by the formation of a National Commission broadly representative of the government and such bodies" (UNESCO 2020:15). Thus, it is the constitutional obligation of each Member State to set up a National cooperating body (National Commission) or make such institutional arrangements whose principal objective is facilitating involvement of various government Ministries, Organisations and Agencies (MOAs), institutions, universities, NGOs and individuals in the work of the Organisation. While the realisation of UNESCO'S goals is primarily entrusted in governments, the National Commissions are expected to function as an indispensable platform where national interests, ideas and cultures are represented and interact. This review describes the contribution of the Malawi National Commission for UNESCO to strengthening communication and information capacities in Malawi to fill a perceived gap in information among some stakeholders both within and outside Malawi.
\end{abstract}

Keywords: Malawi National Commission for UNESCO, digital wellness and information ethics, media policy, access to information 
Development and Communication Studies are fully acknowledged. Users may not tweak or remix and offer this work for sale. The full license may be accessed at https://creativecommons.org/licenses/ by-nc-nd/4.0/

To cite this article: Kondowe, E (2021), Strengthening Communication and Information Capacities in Malawi: Case of the Malawi National Commission for UNESCO, Journal of Development and Communication Studies, 8(2); 21-36. https://dx.doi.org/10.4314/jdcs.v8i2.2

\section{Introduction}

The Constitution of the United Nations Educational Scientific and Cultural Organisation (UNESCO) was adopted on 16 November, 1945 and has been amended by the General Conference 23 times since then. The last amendment was in November 2019.

UNESCO is the only United Nations (UN) agency to have a global network of national cooperating bodies known as National Commissions. The National Commissions are part of the overall constitutional architecture of the organization as it was conceived by its founders. Presently, National Commissions operate in all Member States of UNESCO. They constitute a truly global family which includes a vast network of stakeholders, partners and experts. They offer a comparative advantage to the organisation within the United Nations system.

Article VII (1) of the UNESCO Constitution stipulates that "Each Member State shall make such arrangements as suit its particular conditions for the purpose of associating its principal bodies interested in educational, scientific and cultural matters with the work of the organisation, preferably by the formation of a National Commission broadly representative of the government and such bodies" (UNESCO 2020:15). Thus, it is the constitutional obligation of each Member State to set up a National cooperating body (National Commission) or make such institutional arrangements whose principal objective is facilitating involvement of various government Ministries, Organisations and Agencies (MOAs), institutions, universities, NGOs and individuals in the work of the Organisation.

While the realisation of UNESCO's goals is primarily entrusted to governments, the National Commissions are expected to function as an indispensable platform where national interests, ideas and cultures are represented and interact.

\section{The Malawi National Commission for UNESCO}

The Malawi National Commission for UNESCO was established on 23 ${ }^{\text {rd }}$ March, 1979 through Malawi Government Gazette No. 375, thus complying with Article VII of UNESCO's Constitution. Currently, it is classified as a quasi-statutory organisation as its establishment is not directly backed by an Act of Parliament. The aim of this article is to describe the contribution of the Malawi National Commission for UNESCO (hereinafter the Commission) to strengthening communication and information capacities in Malawi. This has been motivated by a perceived gap in information that 
exists among some stakeholders both within and outside the country, who are important for the work of the Communication and Information Sector despite numerous activities that have been carried out and publicised.

Even though communication and information are not acknowledged in the acronym UNESCO, they have been part and parcel of the organisation from its inception. In a world that solidly affirms the value of freedom of expression, freedom of the press and access to all types of information, it is not surprising that UNESCO's Communication and Information Sector has steadily grown in importance and impact. Article I (2) (a) of UNESCO's Constitution states that in order to realise its purpose the organisation will "Collaborate in the work of advancing the mutual knowledge and understanding of peoples, through all means of mass communication and to that end recommend such international agreements as may be necessary to promote the free flow of ideas by word and image" (UNESCO 2020:6).

The Commission in Malawi has not been left behind in seizing the opportunity to strengthen communication and information capacities in Malawi so that the country derives the maximum benefit possible from opportunities offered by UNESCO's programming. It has made significant contributions in shaping Malawi's media landscape.

\section{Support to public policy and legislative related processes}

The Commission's interventions have been at both the policy level and the legislative level. At the policy level, it has been through providing financial and technical support for the development of the media policy and from the legislative point of view, it has been through financial support to identify pieces of legislation that are potential obstacles to the operation of the media in Malawi as well as popularising the Access to Information legislation.

\section{Support for the formation of the media policy for Malawi}

\section{Defining public policy}

It is important, before detailing some activities that the Commission has supported in the context of the development of the Malawi media policy, to discuss, however briefly, definitions of public policy offered by some authors, if only to situate policy issues in academic discourse and appreciate the aims and importance of public policy documents. Like the definition of any concept, defining the term public policy is not a simple exercise. Torjman (2005) seems to share this view when he states that there is no simple answer to the question 'What is policy?' as it transcends multiple sectors of government action. "Public policy determines the quality of the air we breathe and the water we drink. It affects the food we eat-how it is harvested, where it is distributed and sold, and how much we pay" (Torjman 2005:1).

According to Anyebe (2018), merely defining public policy as what government intends to do to achieve certain goals is not satisfactory as it makes public policy look 
like a mere decision or a simple declaration of intentions, wishes, principles, or expression of desires. His view is that "Public policy should mean actual resource allocation presented by projects and programmes designed to respond to perceived public problems and challenges requiring government action for their solution. That is, it should mean hard patterns of resource allocation presented by projects and programmes designed to respond to perceived public demands" (Anyebe 2018:8). This is an important observation especially for Malawi, a country that has built a commendable reputation for producing quality documents that are either just piled to gather dust or are half-heartedly implemented due to lack of resource allocation.

Swanepoel (2002:6) is one of those who provide a simplified definition of public policy as "a set of measures (or behaviours) enacted by government to redress some problematical situation or to achieve a certain goal". An even shorter version focusing on the objective is advanced by Torjman (2005:4) who states that "In a nutshell, public policy seeks to achieve a desired goal that is considered to be in the best interest of all members of society". There are several other definitions. An interesting one is the one advanced by Anderson (1984:2-3) who defines policy as "a proposed course of action of a person, group or government within a given environment providing obstacles and opportunities which the policy was proposed to utilise and overcome in an effort to reach a goal or realise an objective or a purpose". As Swanepoel (2002) aptly puts it, one important aspect of the definitions is whether it focuses on the descriptive or normative point of the concept of public policy. In other words, the question becomes whether the definition looks at what a public policy is in real life or what it is supposed to be. Apart from that the definitions cited above incorporate, in one way or the other, goals, methods and strategies.

\section{Proposed media policy 2003}

Following the adoption of the 1995 Constitution through which Malawi reverted to a multiparty political system, it became all too apparent that there was an urgency for practically all sectors of government to talk to the provisions of the Constitution. By 2003, Malawi had made major strides in the liberalisation of the media but it was apparent that the area of media policy was still developing. It was due to the absence of a policy specifically setting up democratic parameters for safeguarding media freedom and integrity that the Government of Malawi decided to formulate a media policy.

In 1996 Government had formulated a policy. Somehow that policy was never implemented. It remained shelved until 2002 when UNESCO approved a request for financial assistance towards the formulation of a media policy. Following consultations between the Commission and the Ministry of Information, it was decided to revisit the 1996 policy instead of coming up with a completely new one. Consequently, a technical working group was established and it met at Boadzulu Holiday Resort from 16-18 March 2003. Institutions on the technical group were the Ministry of Information, the Malawi Communications Regulatory Authority (MACRA), the National Media 
Institute of Southern Africa (NAMISA) as MISA-Malawi was known then, the Media Council of Malawi, the Malawi Polytechnic, and the Commission. The final product of the working meeting of the Technical Committee was the Draft Media Policy which was reviewed by stakeholders at the Shire Highlands Hotel Consultation which took place from 5-6 June 2003. At the end of the consultation participants adopted a draft of the Malawi Media Policy of 2003.

Another meeting now organised by the Ministry of Information was held in 2006. It revised the 2003 policy which was once again not implemented. Former Director of Information, Gideon Munthali, indicated in a phone conversation in 2018 that what still exists is the 2006 policy which is being revised. This author is not aware of the latest developments on the issue.

\section{Policy analysis and consultation on the integration of communication and information policies}

Considering the goals, objectives and purposes of policies, it is only proper that they should be formulated in such a way that they constitute a clear, unambiguous and coherent guide. That is why the Commission sought some assistance from UNESCO to evaluate some policies in the Communication and Information Sector in Malawi. This was one way of determining the effectiveness of processes that led to their formulation. The evaluation was also one way of establishing whether or not the policies had common aspects that could make it possible to integrate them into two or one documents. This followed the observation that there was a proliferation of policies in the communication and information sector.

The Draft Media Policy (2003) and the Communications Sector Policy 1998 were singled out for evaluation. The main recommendation of the evaluation of the Draft Media Policy (2003) were that it should be maintained separate from the Communications Sector Policy as the overlaps were minimal and did not therefore justify merging. The main finding of the evaluation of the Communications Sector Policy (1998) was that there was need to put in place mechanisms for ensuring that chief executives for the Malawi Communications Regulatory Authority (MACRA), Malawi Broadcasting Corporation (MBC) and Television Malawi (TVM) were adequately protected from political manipulation. Appointment through the Public Appointments Committee (PAC) of Parliament was considered to be one option. Another aspect of this initiative was consultations with the Ministry of Information, TVM, MBC and MACRA. One important recommendation that came out of interviews with management of MBC and TVM was the need to merge MBC and TVM both of which were getting Government subvention. No justification was established to depart from the practice in other countries.

\section{Emergence of Community Radio Broadcasting}

Literature shows that various political, social and regulatory developments have catalysed the recent emergence of community radio broadcasting in various countries. 
In some cases the emergence of community radios has been influenced by international organisations agendas for use of community radios as tools for promoting and supporting socio-economic development. However, the general pattern appears to show links to efforts by interest groups or development partners or both and presence of favourable legislation mainly constitutional provisions.

\section{Defining community radio broadcasting}

There are various definitions of community radio. Some have been advanced by different authors or groups while other definitions have been legally determined by pieces of legislation. It could be argued that definitions fall into two groups namely the academic definitions advanced by scholarly literature and operational definitions set as standards by legislation. Seneviratne (2011:132) defines a community radio station as "one that is operated in the community, for the community, about the community and by the community". The author further states that the community can be territorially or geographically bounded or it can be a group of people with common interests who might be geographically separated. The idea of a geographically bounded community is also shared by Pandey (2010) who observes that since a community radio implies that people should have access to it, the communities need to be geographic entities that can be reached by the signal from the radio.

\section{Importance of community radio}

Community radio enables individual community members identify with and own development initiatives taking place in their communities. Studies carried out to establish the importance of community radios have mostly shown that community radio is an important instrument for the participation of individuals in the activities of their communities. One such study was conducted by the Association of Community Radio Broadcasters (AMARC). The objective was to identify challenges to the positive impact of community radio and to find the best possible ways to enhance its role in poverty reduction, development, inclusiveness and democracy building in local communities. The study showed that communities see community radios as a means of expressing their own issues, concerns, cultures and languages (AMARC 2007).

Osman (2008) carried out a case study of some community radio stations in Malawi to explain the state of practice of community radio in Malawi and its impact on grassroots audiences. Among his conclusions was the fact that community radios enable citizens to debate and discuss issues important for the communities and that it enhances political participation. He also concluded that community radio broadcasting can help local government institutions by providing a conducive atmosphere for operating transparently. Banda (2004:60) points at clear "geographic and societal (including linguistic) necessities for the expansion and development the community radio sector".

Following their study of seven community radio stations in Ghana, Diedong and Naaikuur (2012) established that community radios made it possible for people to 
understand their rights and responsibilities with regard to natural resources which resulted in sustainable use of the resources. The study also established that the community radio facilitated innovative approaches to the process of communication by making it possible for listeners to intelligently use the media and discuss important issues using local languages.

The authorities in Malaysia were of the view that community media should be considered a very important part of a decentralised democratic process as ownership is with locals making broad public participation possible. However, they were of the view that for the radios to flourish, there had to be a "democratic government strong enough not to be threatened by the proliferation of alternate political views that might be projected through these channels" (Magpanthong \& McDaniel, 2011:125).

In an examination of Bush Radio and Radio Zibonele in South Africa, Olorunnisola (2002) observed that both stations were used as channels for dissemination of information on daily issues about the communities they serve in an interactive way. They also facilitated the acquisition of knowledge for navigating the multiracial democratic culture. "In post-independent Zimbabwe, the re-emergence clandestine radio provided opportunities for individuals and groups generally excluded by mainstream government controlled media to discuss various issues" (Moyo 2010:34).

It is evident from the literature cited here that community radio broadcasting is mostly considered an important tool for various social, political and developmental endeavours. It is important therefore that its potential be fully and effectively exploited by communities.

\section{Community radio broadcasting in Malawi \\ Status of the broadcasting sector}

Malawi's broadcasting sector has made considerable progress. The monopoly previously enjoyed by the public national broadcaster that has so far been a government radio for the party in power, even over twenty-five years after the multiparty general elections of 1994, Malawi Broadcasting Corporation (MBC), is no longer there. Private national broadcasters, national community of interest broadcasters and geographic community radio broadcasters have since emerged, thanks to the initiatives of various organisations (including political parties) and individuals. One of the sub-sectors that has gained popularity is community radio broadcasting.

Undoubtedly one of the major players in the emergence of the community radio broadcasting sector in Malawi is the Commission whose efforts started with the establishment Dzimwe Community Radio Station in 1998. It was the first geographical community radio station in Malawi and was established with financial and technical assistance from UNESCO through the Commission. The assistance followed a submission under the programme that was called "Women speaking to women". The objective of this particular programme was to give rural women a platform from which they could articulate challenges they face in their communities and together identify 
ways of effectively facing such challenges. The project document which the Commission developed identified the Malawi Media Women's Association (MAMWA) as implementers of the project. It was considered important to have a group of professional women who could impart broadcasting skills to the rural women in Monkey Bay and eventually hand over the radio station to the rural women after an adequate transfer of knowledge and skills.

\section{Request submission method}

While the document that established Dzimwe Community Radio Station was developed at the initiative of the Commission, documents for the other five were developed following requests by members of the communities. For all radio stations the District Development Committees were made part of the process of establishing the radio so as to avoid political interference and individualisation of the radio projects. In that context, it did not matter who submitted the project as long as it was submitted through the office of the District Commissioner or it was understood that it was for the community.

At a needs assessment study conducted in preparation for a training workshop in 2017, it was established that apart from Usisya Community Radio Station which did not provide any information on whether or not the community was consulted prior to the establishment of the radio, the other five indicated that the communities were consulted (Malawi National Commission for UNESCO 2017). At the writing of this article, there were six community radio stations established with financial and technical assistance from UNESCO through initiatives of the Commission. These community radio stations are Dzimwe (Monkey Bay), Nyanthepa (Nsanje), Nkhotakota (Nkhotakota), Likoma (Likoma and Chizumulu Islands), Chirundu (Nkhata Bay) and Usisya (Nkhata Bay).

\section{Benefits}

All these community radios were established "to afford rural communities and especially the disadvantaged in those communities like women and the youth, the opportunity to access and share information for their individual benefit and for the development of their communities" (Malawi National Commission for UNESCO and Editions Afrique Océanie, 2006:90).

\section{Challenges}

During one of the training sessions for the community radios, participants identified the following as some of the challenges they face:

1. Lack of stability in funding sources;

2. Increased competition following the establishment of many radio stations some with signals that reach the areas where the community radios are;

3. High staff turnover;

4. Limited coverage due to technical problems associated with equipment; 
5. Boards that do not seem to understand their roles;

6. Power problems resulting in radios frequently going off air;

7. Lack of reliable means of transport; and

8. Poorly resourced in terms of ICTs

It is, however, not all doom and gloom. Dzimwe Community Radio Station now has its own purpose-built building and has established cooperation with several partners. Nkhotakota Community Radio Station has won some MISA Malawi Awards and has bought a vehicle and a generator. Nyanthepa Community Radio Station has secured a generator and a motor cycle and has also established some partnerships.

\section{Support to the Department of Journalism and Media Studies at the Malawi Polytechnic}

The Commission was one of the first organisations to support the degree programme introduced by the Department of Journalism and Media Studies at the Malawi Polytechnic then part of the University of Malawi. The first support was purchase of computers for use by students in the department. The assistance was provided by UNESCO's International Programme for the Development of Communication (IPDC) in 1998.

The Commission later purchased books and published on the history, progress and prospects of journalism in Malawi. This assistance was provided to enhance the capacity of the Malawi Polytechnic to offer high quality media training and journalism education and also to publish a book on journalism that would talk about Malawi. The book that was eventually published, thanks to the collaboration between the Commission and the Polytechnic, is titled Journalism Practice in Malawi: History, Progress and Prospects. It is being used in many journalism programmes in Malawi and beyond as an authoritative source on Malawian journalism.

ICT skills for young journalists for researching information on education, science, social and human sciences, culture and communication and information

The purpose of the activity was to assist journalists in Malawi keep pace with technological advances relevant to the practice of journalism in today's globalised society. In line with this need, the objectives were to impart email and Internet surfing skills; to impart skills in researching issues pertaining to education, science, social and human sciences, culture and communication and information and promote intersector collaboration.

\section{Capacity building activities}

The Commission has been organising a many capacity building activities for journalists and other groups such as Parliamentarians and the Malawi Police service on the role of 
the media. These activities have mainly focused on capacity building intended to strengthen the professional capacities of journalists. A few will be highlighted here.

\section{Capacity building for the media}

\section{Training seminar for the independent media in Malawi}

This seminar was organised in the days when the country was preparing for elections that would bring back a multiparty-system of Government. At that time the independent media were considered such in the sense that they were offering alternative view points to the political establishment. Normally, working with such media would have been considered oppositional to the political establishment. It is the author's belief that the Malawi National Commission for UNESCO was able to get away with such activities because of the name UNESCO at a time when the political establishment would have been wary of antagonising the international community further. Many, especially politicians, did not and still do not, understand how UNESCO is operationally structured.

\section{Training seminar for Malawi Broadcasting Corporation (MBC) and Malawi Television Malawi (TVM) managers}

This workshop took place in 2005. It was conceived following the licencing of MBC and TVM as public broadcasters which licencing meant that the two media houses had to embrace and follow the philosophy of public broadcasting as opposed to state broadcasting. Accordingly, the objectives of the workshop were to:

1. promote awareness by public broadcasting managers of the need for editorial independence;

2. create an appreciation of the uniqueness of public service broadcasting; and

3. enable managers reassess their role in light of the change from state broadcasters to public service broadcasters.

\section{Second media workshop on monotheistic religions}

The workshop was part of the UNESCO programme for the promotion of dialogue amongst the major civilisations and religions of the world. The promotion of dialogue in the service of peace-in order to construct the defences of peace in the minds of men (UNESCO 1945) [the phrase has now been changed to construct the defences of peace in the minds of men and women]- is one of the main themes of UNESCO's mission. UNESCO sponsored the workshop in order to help and encourage people in the media in their vital role of promoting tolerance and understanding by overcoming what elsewhere has been described as 'the still prevailing ignorance of each other's ways and lives' among peoples of different faiths. The main objective of this activity was to equip participants with relevant information about the main beliefs and practices of Christians and Moslems, with the emphasis on what they share and where they differ and also about variety within the two religions. 


\section{Training of journalists in the coverage of elections}

The aim of the training was to contribute to the improvement of the standards of coverage of the electoral process and help journalists strategise on the coverage of the 2009 Presidential and Parliamentary Elections in such a way as to make the coverage more meaningful and beneficial to the voter. During the training, the Malawi Electoral Commission stated what it expected from the media, namely that the media would help convince people to go and vote, explain party manifestos to the public, and provide balanced and impartial reporting.

\section{Role of the media in providing humanitarian information in emergencies and disasters}

Since 1990, the frequency and magnitude of disasters to which Malawi is prone has steadily increased with the result that more people are affected. This increased trend is attributed to climate change, population growth and urbanisation. Common hazards in Malawi include floods and landslides (due to heavy storms), droughts resulting in pest infestations and accidents (such as fires), disease epidemics and earthquakes.

Heavy rains experienced in the first quarter of 2015 for example, caused flooding in 15 of the 28 districts in Malawi, most of which are located in the southern part of the country affecting over 684,700 people. On the diseases front, by June 2015, there were 693 reported cases of cholera and 11 deaths.

In 2018, Malawi experienced the most severe prolonged dry spells and fall army worm infestation which wreaked havoc on agricultural production of 3.8 million people (Ministry of Agriculture, Irrigation and Water Development Report 2018). With little rain falling in some parts and or no rain falling in other parts of the country and fall army worms still destroying crop fields the outlook was alarming. It was expected to result in hunger affecting over 3.8 million people up to next growing season (Ministry of Agriculture, Irrigation and Water Development Report 2018). Even before the prolonged dry spells, the Malawi Government had declared drought a national disaster in December 2017 because of fall army worms. When disasters occur, it is mostly women who are affected. Women are first responders but usually face the brunt of the disaster through abuse, loss of property, loss of loved ones and lack of immediate assistance.

Like in many other areas of human endeavour, the media is an important partner in providing information in times of emergencies and disasters. Information disseminated by the media can:

1. reduce of loss of life and property due to early warnings of natural hazards helping to minimise recovery costs hence resources can be redirected to other areas of development;

2. help make the public aware of impending hazards and provide advice to take appropriate action to ascertain their wellbeing, and help simplify technical information provided by government Ministries, Departments and Agencies (MDAs) which might be difficult to understand due to illiteracy levels. 
The aim of the initiative was to improve media coverage of news and information on emergencies and disasters related to climate change. The objectives were to:

- assess sources of information for the media on how to report on emergency and disasters arising from climate change;

- develop media guidelines on reporting emergency and disasters arising from climate change;

- conduct training of journalists;

- encourage greater participation of women in reducing the effects.

\section{Information and Communication Technologies (ICT) training for women in gender and human rights NGOs}

Advances in ICTs have become central to the process of human development. Marcelle (2000) observes that ICTs are a complex and heterogeneous set of goods, applications and services used for producing, distributing, processing and transforming information. Their use has made possible the phenomenal progress human beings have made in gathering, processing, disseminating and using information. Societies are now required to promote new skills and knowledge, to adapt and cope with a rapid pace of skills acquisition, to effectively apply new skills and knowledge. Unfortunately there are gender disparities in the capacity to harness the potential of ICTs. They do not favour women who form part of excluded and marginalised groups who never have the skills required nor the ability and resources to acquire the necessary skills.

The Millennium Declaration adopted in 2000 underscored the urgency of ensuring that benefits of new technologies, especially ICT, are made available to all. The training was organised in the context of the foregoing. It was meant to impart knowledge and skills to women so that they could benefit from the exploitation of ICTs just as much as men as the participation of women in information technology design and development is generally low.

Training of Parliamentarians on the role of the media in democracy Boadzulu Holiday Resort in Mangochi from 25-29 November 2001

Parliaments are at the centre of the notion of representative government which depends very much on transparency and accountability. Since the press plays a critical role in facilitating transparency and accountability, it was only logical to ensure that parliamentarians appreciate the role of the press in a democratic governance. As members of the Malawian society mandated to pass legislation, the impact of their actions on the creation of a conducive atmosphere for the operation of the media is beyond debate.

The training covered the following topics:

1. The Role of the media in democracy and decentralisation: The essence of this topic was to draw the attention of participants to the fact that for Malawians to realise the full opportunities and benefit from the principles of a truly democratic country, there was need to strengthen structures and avenues for political participation of which the media was one.

2. Media and electoral processes: This topic focussed on giving the participants a wide understanding of the role of the media in electoral processes by among other issues, explaining the need to clarify messages from those seeking political office, encouraging 
the electorate to participate in elections either as candidates or voters and to denounce electoral misbehaviour.

3. The role of the media in promoting transparency and accountability: The objective of this topic was to enable participants understand transparency and accountability, democracy as a participatory governing process and introduce them to "pillars of democracy" namely the Office of the Ombudsman, the Human Rights Commission, the Law Commission, the Anti-Corruption Bureau and Non-Governmental Organisations whose role is to ensure that government and other public officers carry out their jobs honestly, openly and responsibly.

- The media as the Fourth Estate: Among other issues, what was discussed under this topic was that since in a democracy, elected representatives are answerable to the electorate, it was only right and proper for the media to be accountable to the public not to Parliament or any other institution. The media gets its authority to act as the fourth arm of Government from the people.

- Human rights education: One of the main issues which the topic covered was the importance of human rights education, namely that it is a source of knowledge and that it enables people develop certain attitudes and values which are in line with democracy.

- Basic documents recognising the principles of press freedom: The topic drew attention to the fact that the role the media can play in a democracy depends very much on the extent to which the law protects freedom of expression and media freedom. In that context, the Constitution of the Republic of Malawi was described as one of the instruments that protects media freedom as it has provisions for the gathering and dissemination of information, ideas and opinions. The topic also emphasised the fact that though circumstances can arise for limiting freedom of expression, freedom of the press and other human rights, such limitations must be prescribed by law, be reasonable, be recognised by international human rights standards, and must be necessary in an open and democratic society.

\section{Provision of Mobile Video Vans to the Department of Information}

In 1992 UNESCO's IPDC purchased mobile video vans for the Department of Information. It followed a request by the department. The request was born out of the need to reach rural areas communities on issues pertaining to literacy, health, agriculture, social welfare, population and the environment.

\section{Computerisation of the Malawi Broadcasting Corporation Newsroom}

In 1996 the IPDC approved a request to computerise news processing at the Malawi Broadcasting Corporation (MBC) so as to ensure efficiency in the processing of news. Further assistance was provided in 1999 by the Government of France but through the IPDC. 


\section{Support to Television Malawi}

UNESCO, through the Commission has in the past provided assistance to $\mathrm{MBC}$ Television (MBC-TV), then known as Television Malawi (TVM) on three occasions. The first time financial assistance was provided for the purchase of some equipment in 1998. During the same year, the UNESCO Film and Video Training Project organised a sixweek training course for 30 personnel from TVM. The aim of the training was to help TVM organise itself in a manner that would enable the station deliver her local content programming requirements. The course covered journalism practice and camera, sound, editing and production management.

In March 2002, a fire broke out at the building housing TVM at Njamba destroying the only studio including equipment such as the central air conditioner, lights, studio sets, graphic computers and many other such equipment. In view of the fact that the station had become very popular in the short period of its existence and that it was disseminating information that was important for the Malawian public, the Commission felt duty bound to request UNESCO for emergency assistance and it was provided.

\section{Sensitisation on Access to Information Bill}

Section 37 of Malawi's Republican Constitution provides for the "the right of access to information held by the State or any of its organs at any level of government in so far as such information is required for the exercise of his rights". In 2008 the enabling legislation to the right of access to information had not yet been passed as Government kept on saying that it was still being worked on. Stakeholders understood that in order for the bill to be passed into an Act it had to be understood and accepted by Parliamentarians, public servants and the general public had to be aware of the rights envisioned in the bill. It was for those reasons that the Commission sought assistance to carry out sensitisation activities around the bill.

Some activities foreseen in the conceptualisation of the initiative were overtaken by events. The training seminar targeting senior government officials and the other meant for Parliamentarians had already been conducted by MISA-Malawi (then National Media Institute for Southern Africa- NAMISA) with financial assistance from other cooperating partners. The Commission, therefore, focused on the Police Service. Senior civil servants and Parliamentarians were, nevertheless, still adequately covered through the panel discussions which were structured in such a way that apart from targeting the general public, they were also of immense significance to public servants and Parliamentarians. 


\section{Promotion of digital wellness and information ethics awareness and knowledge in Girls Secondary Schools in Malawi}

The youth, especially girls, are a particularly vulnerable group when it comes dangers and abuse arising from the use of the media and the Internet. This is why the need for media literacy ICT in Malawian secondary schools cannot be overemphasised.

When students join universities from secondary schools, most of them lack the skills of locating and evaluating information especially in its digital form and this limits its effective use. It becomes important for them to be empowered with the knowledge and skills to access, evaluate and use information effectively. This is especially important because the availability of the mass of electronic resources in university libraries, the internet, websites and Webpages is growing rapidly and the platforms are also readily accessible resulting in the challenge of using information effectively and responsibly.

This state of affairs is what led to the conception of this initiative. A manual for secondary school teachers and a manual and another for secondary school students were produced under the initiative. Secondary school teachers were trained so that they could go and train students on media literacy, cyber wellness and information ethics.

\section{Conclusion}

The benefits from UNESCO's Communication and Information activities outlined above have been many and varied. They include giving momentum to policy and legislative issues, training of journalists, providing equipment to media organisations, supporting MISA-Malawi activities and establishing and popularising community radios.

On the downside, being the poorer cousin in the United Nations system, assistance from UNESCO is basically meant to get things going and is thus usually rarely substantial for certain projects. This also means that some important areas falling within UNESCO's mandate are not addressed or are taken over by other development partners. There is however a face saver these days as assistance is put under the umbrella term of United Nations but a scrutiny of the financial muscle would show that the smallest amount comes from UNESCO.

\section{References}

AMARC. 2007. Community radio social impact assessment: Removing barriers, increasing effectiveness. Montreal: AMARC.

Banda, F \& Fourie, PJ. 2004. Towards a policy model for community radio broadcasting in Zambia. Communication: South African Journal for Communication Theory and Research 30 (2):50-83.

Diedong, AL \& Naaikuur, L. Ghana's experience in participatory community radio broadcasting. Global Media Journal African Edition 6(2):123-147. 
Magpanthong, C \& McDaniel, D. 2011. Media democratization at the crossroads: community radio in Thailand and Malaysia. Journal of Radio and Audio Media 18(1):116-128).

Malawi National Commission for UNESCO and Editions Afrique Océanie. 2006. Information Magazine No. 1

Malawi National Commission for UNESCO and Editions Afrique Océanie. 2007. Information Magazine No. 2

Malawi National Commission for UNESCO.2017. Capacity building for community radio stations for sustainability (unpublished).

Moyo, D. 2010. Reincarnating clandestine radio: Rural radio forums in post-independent Zimbabwe. African Journalism Studies 28(1\&2):11-29.

Olorunnisola, AA. 2002. Community radio: Participatory communication in post-apartheid South Africa. Journal of Radio Studies 9(1):126-145.

Osman, A. S. 2008. Is community radio promoting social change in Malawi? Unpublished Master's dissertation. Leicester: Leicester University.

Swanepoel, P. (2002). Working with public policy documents: setting up an analytical tool box. UNISA. Department of Communication Science.

Pandey, V. 2010. Community radio: Radio's new incarnation. Global Media Journal: Indian Edition. Summer Issue/June 2010:1-7.

Seneviratne, K. 2011. Community radio via public service broadcasting: The Kothmale model. Journal of Radio \& Audio Media 18(1) 2011:129-138.

UNESCO. 1945. Constitution of the United Nations Educational, Scientific and Cultural Organisation. London.

UNESCO. 2020. Constitution of the United Nations Educational, Scientific and Cultural Organisation. 2020 Edition (Revised Edition). Paris. France. 